\title{
Content
}

\section{Instrumentation and Methods}

Aberration corrected STEM and EELS: Atomic scale chemical mapping ................ 1 A.L. Bleloch, M. Gass, L. Jiang, B. Mendis, K. Sader, and P. Wang

An update on the TEAM project - first results from the TEAM 0.5 microscope, and its future development

U. Dahmen, R. Erni, C. Kisielowki, V. Radmilovic, Q. Ramasse, A. Schmid, T. Duden, M. Watanabe, A. Minor, and P. Denes

Synchrotron based X-ray Microscopy: state of the art and applications 5

J. Susini

High-resolution spectro-microscopy with low-voltage electrons and double aberration correction 7

T. Schmidt, H. Marchetto, R. Fink, E. Umbach, and the SMART collaboration

\section{I1 TEM and STEM instrumentation and Electron Optics}

\section{I1.1 Aberration Correctors}

Developments of aberration correction systems for current and future requirements 9

M. Haider, H. Müller, S. Uhlemann, P. Hartel, and J. Zach

STEM Aberration Correction: an Integrated Approach 11

O. Krivanek, N. Dellby, M. Murfitt, C. Own, and Z. Szilagyi

Applications of aberration-corrected TEM-STEM and high-resolution EELS for the study of functional materials.

G. A. Botton, C. Maunders, L. Gunawan, K. Cui, L.Y. Chang, and S. Lazar

Aberration corrected TEM and STEM for dynamic in situ experiments

P.L. Gai and E.D. Boyes

HREM study of the $\mathrm{SrTiO}_{3} \Sigma 3$ (112) grain boundary

K.J. Dudeck, N. Benedek, and D.J.H. Cockayne

A Method to Measure Source Size in Aberration

Corrected Electron Microscopes

C. Dwyer, J. Etheridge, and R. Erni

Determining resolution in the transmission electron microscope:

object-defined resolution below $0.5 \AA$

B. Freitag and C. Kisielowski 
Direct measurement of aberrations by convergent-beam electron holography (CHEF)

C. Gatel, F. Houdellier, and M.J. Ḧ̈tch

Atomic Structure of $\mathrm{BiFeO}_{3}-\mathrm{BiCrO}_{3}$ film on (111) $\mathrm{SrTiO}_{3} \mathrm{Grown}$

by Dual Cross Beam Pulsed Laser Deposition

L. Gunawan, R. Nechache, C. Harnagea, A. Pignolet, and G.A. Botton

Demonstration of $\mathbf{C}_{\mathbf{C}} / \mathbf{C}_{\mathrm{S}}$-correction in HRTEM

P. Hartel, H. Müller, S. Uhlemann, J. Zach, U. Löbau, R. Höschen, and M. Haider

New electron diffraction technique using Cs-corrected annular LACDIF: comparison with electron precession

F. Houdellier and S. Bals

The newly installed aberration corrected dedicated STEM (Hitachi HD2700C) at Brookhaven National Laboratory

H. Inada, Y. Zhu, J. Wall, V. Volkov, K. Nakamura, M. Konno, K. Kaji, K. Jarausch, and R.D. Twesten

Uranium single atom imaging and EELS mapping using aberration corrected STEM and LN2 cold stage

H. Inada, J. Wall, Y. Zhu, V. Volkov, K. Nakamura, M. Konno, K. Kaji, and K. Jarausch

Sub-Ångstrøm Low-Voltage Electron Microscopy - future reality

for deciphering the structure of beam-sensitive nanoobjects?

U. Kaiser, A. Chuvilin, R.R. Schröder, M. Haider, and H. Rose

Detecting and resolving individual adatoms, vacancies, and their dynamics on graphene membranes.

J.C. Meyer, C. Kisielowski, R. Erni, and A. Zettl

Scanning confocal electron microscopy in a double aberration corrected transmission electron microscope

P.D. Nellist, E.C. Cosgriff, G. Behan, A.I. Kirkland, A.J. D'Alfonso, S.D. Findlay, and L.J. Allen

Design of apochromatic TEM composed of usual round lenses 41

S. Nomura

Back-Scattered Electron microscopy in Aberration

corrected Electron microscope.

E. Okunishi, Y. Kondo, H. Sawada, N. Endo, A. Yasuhara, H. Endo, M. Terao, and T. Shinpo

Structure determination of $\mathrm{H}$-encapsulating clathrate compounds in aberration-corrected STEM

Q.M. Ramasse, N.L. Okamoto, D. Morgan, D. Neiner, C.L. Condron, J. Wang, P. Yu,

N.D. Browning, and S. Kauzlarich

Performance of R005 Microscope and Aberration Correction System 47

H. Sawada, F. Hosokawa, T. Kaneyama, T. Tomita, Y. Kondo, T. Tanaka, Y. Oshima,

Y. Tanishiro, N. Yamamoto, and K. Takayanagi 


\section{I1.2 Filters, Spectrometers, Monochromators and Sources}

Optimum operation of Schottky electron sources:

brightness, energy spread and stability

P. Kruit, M.S. Bronsgeest, and G.A. Schwind

The MANDOLINE filter and its performance

E. Essers, D. Mittmann, T. Mandler, and G. Benner

Using a monochromator to improve the resolution in focal-series reconstructed TEM down to $0.5 \AA$

P.C. Tiemeijer, M. Bischoff, B. Freitag, and C. Kisielowski

First performance measurements and application results of a new high brightness Schottky field emitter for HR-S/TEM at 80-300kV acceleration voltage

B. Freitag, G. Knippels, S. Kujawa, P.C. Tiemeijer, M. Van der Stam, D. Hubert,

C. Kisielowski, P. Denes, A. Minor, and U. Dahmen

Image Information transfer through a post-column energy filter detected by a lens-coupled CCD camera

U. Luecken, P. Tiemeijer, M. Barfels, P. Mooney, B. Bailey, and D. Agard

Third-rank computation of electron and ion optical systems with several and rotated Wien filters

K. Marianowski and E. Plies

Wavelength dispersive soft X-ray emission spectroscopy attached to TEM using multi-capirary X-ray lens

S. Muto, K. Tatsumi, and H. Takahashi

Miniature electrostatic-magnetostatic column for electrons

C. Rochow, T. Ohnweiler, and E. Plies

Comparison of monochromated electron energy-loss with X-ray absorption near-edge spectra: ELNES vs. XANES

T. Walther and H. Stegmann

A hybrid electron energy loss spectrometer with simultaneous serial and parallel detection

J. Yuan, Z. Wang, S. Hu, and L. Xie

\section{I1.3 Phase Plates and Detectors}

In-focus phase contrast: Present state and future developments

R.R. Schröder, B. Barton, K. Schultheiß, B. Gamm, and D. Gerthsen

The Detective Quantum Efficiency of Electron Area Detectors .71

R. Henderson, G. McMullan, S. Chen, and A.R. Faruqi 
Experimental observation of the improvement in MTF from backthinning a CMOS direct electron detector 73

G. McMullan, A.R. Faruqi, R. Henderson, N. Guerrini, R. Turchetta, A. Jacobs, and G. van Hoften

High speed simultaneous $X$-ray and electron imaging and spectroscopy at synchrotrons and TEMs

L. Strüder

The image intensity in Zernike mode with electrons. 77

M. Beleggia

Application of a Hilbert phase plate in transmission electron microscopy of materials science samples

M. Dries, K. Schultheiß, B. Gamm, H. Störmer, D. Gerthsen, B. Barton, and R.R. Schröder

Optimal Imaging Parameters in Cs-Corrected Transmission Electron Microscopy with a Physical Phase Plate. 81

B. Gamm, K. Schultheiss, D. Gerthsen, and R.R. Schröder

Electron optical design of the Phase Aberration Corrected

Electron Microscope

M. Matijevic, S. Lengweiler, D. Preikszas, H. Müller, R.R. Schröder, and G. Benner

Direct electron detectors for TEM 85

G. Moldovan, X. Li, P. Wilshaw, and A.I. Kirkland

A Newly Developed 64 MegaPixel camera for Transmission

Electron Microscopy

H.R. Tietz

Characterization of a fiber-optically coupled 8k CCD/CMOS device 89

D. Tietz, H. Tietz, S. Nickell, W. Baumeister, and J.M. Plitzko

Direct Single-Electron Imaging using a pnCCD Detector 91

A. Ziegler, R. Hartmann, R. Andritschke, F. Schopper, L. Strüder, H. Soltau, and J.M. Plitzko

\section{I2 TEM and STEM methods}

\section{I2.1 Quantitative HRTEM and STEM}

Quantitative TEM and STEM Simulations 93

C.T. Koch

Quantitative determination of the chemical composition of an alloy by High Angle Annular Dark Field imaging. 95

V. Grillo, F. Glas, and E. Carlino 
The benefits of statistical parameter estimation theory for quantitative interpretation of electron microscopy data

S. Van Aert, S. Bals, L.Y. Chang, A.J. den Dekker, A.I. Kirkland, D. Van Dyck, and G. Van Tendeloo

First time quantification of the HRTEM information-limit reveals insufficiency of the Young's-fringe test

J. Barthel and A. Thust

Quantitative Investigations of the Depth of Field in a Corrected

High Resolution

Transmission Electron Microscope

J. Biskupek, A. Chuvilin, J.R. Jinschek, and U. Kaiser

Quantitative characterisation of surfaces on bi-metallic Pt nanoparticles using combined exit wave restoration and aberration-corrected TEM. 103

L.Y. Chang, C. Maunders, E.A. Baranova, C. Bock, and G. Botton

An HAADF investigation of AIAs-GaAs interfaces using SuperSTEM 105

A.J. Craven, P. Robb, and M. Finnie

Spatial Coherence and the Quantitative Interpretation

of Atomic Resolution Images.

C. Dwyer and J. Etheridge

Analysis of HRTEM diffractograms from amorphous materials:

a simple and minor (but not explained so far?) question revisited

T. Epicier

HAADF-STEM image simulation of large scale nanostructures

P. Galindo, J. Pizarro, A. Rosenauer, A. Yáñez, E. Guerrero, and S.I. Molina

Aberration-corrected HRTEM study of incommensurate misfit layer compound interfaces

M. Garbrecht, E. Spiecker, W. Jäger, and K. Tillmann

Influence of atomic displacements due to elastic strain in HAADF-STEM simulated images

E. Guerrero, A. Yáñez, P. Galindo, J. Pizarro, and S.I. Molina

Effects of electron channeling in HAADF intensity

M. Haruta, H. Komatsu, H. Kurata, M. Azuma, Y. Shimakawa, and S. Isoda

Analysis of the mechanism of $\mathrm{N}$ incorporation in $\mathrm{N}$-doped GaAs

quantum wells

M. Herrera, Q.M. Ramasse, N.D. Browning, J. Pizarro, P. Galindo, D. Gonzalez,

R. Garcia, M.W. Du, S.B. Zhang, and M. Hopkinson

Coherence of high-angle scattered phonon loss electrons and their relevance to TEM and STEM ADF Stobbs Factors

R.A. Herring 
Strain measurements in electronic devices by aberration-corrected HRTEM and dark-field holography

F. Hüe, F. Houdellier, E. Snoeck, V. Destefanis, J.M. Hartmann, H. Bender, A. Claverie, and M.J. Hÿtch

PPA: An Improved Implementation of Peak Pairs procedure as a DM plug-in for Strain Mapping

K. Ishizuka, P. Galindo, J. Pizarro, and S.I. Molina

Domain structure in Delithiated $\mathrm{LiFePO}_{4}$, a cathode material for $\mathrm{Li}$ ion

Battery Applications

M. Kinyanjui, A. Chuvilin, U. Kaiser, P. Axmann, and M. Wohlfahrt-Mehrens

New Approach to Quantitative ADF STEM

J.M. LeBeau, S.D. Findlay, L.J. Allen, and S. Stemmer

Reconstruction of the projected crystal potential in high-resolution transmission electron microscopy

M. Lentzen and K. Urban

Three-dimensional atomic-scale structure of size-selected nanoclusters on surfaces.

Z.Y. Li, N.P. Young, M. Di Vece, S. Palomba, R.E. Palmer, A.L. Bleloch, B.C. Curley,

R.L. Johnston, J. Jiang, and J. Yuan

Direct retrieval of a complex wave from its diffraction pattern

A.V. Martin and L.J. Allen

HRTEM evaluation of iron in acid treated ground vermiculite from

Santa Olalla (Huelva, Spain)

N. Murafa, C. Maqueda, J.L. Perez-Rodriguez, and J. Šubrt

Bloch wave analysis of depth dependent strain effects in high resolution electron microscopy

P.D. Nellist, E.C. Cosgriff, P.B. Hirsch, and D.J.H. Cockayne

Quantitative local strain analysis of Si/SiGe heterostructures using HRTEM ..... 141

V. Burak Özdöl, F. Phillipp, E. Kasper, and P.A. van Aken

Displacement field analysis around hydrogen implantation induced platelets

(HIPs) in semi-conductors

F. Pailloux, M.-L. David, L. Pizzagalli, and J.-F. Barbot

Thickness effects in Tilted Sample Annular Dark Field Scanning

Transmission Electron Microscopy

A. Parisini, V. Morandi, and S.A. Mezzotero

A novel emission potential multislice method to calculate intensity contributions for thermal diffuse scattering in plane wave illumination TEM

A. Rosenauer, M. Schowalter, J.T. Titantah, and D. Lamoen

Three-dimensional HREM Structure Retrieval

Z. Saghi, X. Xu, and G. Möbus 
Description of electron microscope image details based on structure relaxations with enhanced interaction potentials 151

K. Scheerschmidt

Computation and parametrization of Debye-Waller temperature factors for sphalerite type II-VI, III-V and group IV semiconductors.

M. Schowalter, A. Rosenauer, J.T. Titantah, and D. Lamoen

Structural Investigation of Amorphous/Crystalline Interfaces by Iterative Digital Image Series Matching

K. Thiel, N.I. Borgardt, T. Niermann, and M. Seibt

Novel carbon nanosheets as support foils for ultrahigh resolution TEM studies of nanoobjects

A.S. Sologubenko, A. Beyer, C. Nottbohm, J. Mayer, and A. Gölzhäuser

Quantitative HRTEM studies of reconstructed exit-plane waves retrieved from $C_{\mathrm{S}}$-corrected electron microscopes

M. Svete and W. Mader

Geometrical phase analysis of the 1:1 cation ordered domains in complex perovskite ferroelectrics

C.W. Tai and Y. Lereah

The Stobbs factor in HRTEM: Hunt for a phantom?

A. Thust

Measuring coherence in an electron beam for imaging

T. Walther, K. Atkinson, F. Sweeney, and J.M. Rodenburg

Argand plot: a sensitive fingerprint for electron channelling

A. Wang, S. Van Aert, and D. Van Dyck

Atomic-resolution studies of $\operatorname{In}_{2} \mathrm{O}_{3}-\mathrm{ZnO}$ compounds on aberration-corrected electron microscopes

W. Yu, L. Houben, K. Tillmann, and W. Mader

\section{I2.2 Quantitative diffraction and crystallography}

Advances in automated diffraction tomography

U. Kolb, T. Gorelik, E. Mugnaioli, G. Matveeva, and M. Otten

Identification/ fingerprinting of nanocrystals by precession electron diffraction

S. Nicolopoulos, P. Moeck, Y. Maniette, and P. Oleynikov

On the Origin and Asymmetry of High Order Laue Zone Lines Splitting in Convergent Beam Electron Diffraction.

A. Béché, L. Clément, and J.L. Rouvière

Precession electron diffraction: application to organic crystals and hybrid inorganic-organic materials

E.G. Bithell, M.D. Eddleston, C.A. Merrill, W. Jones, and P.A. Midgley 
Structural studies of amorphous materials using RDF, RMC and DFT refinement

K. Borisensko, Y. Chen, G. Li, D.J.H. Cockayne, and S.A. Song

A Nanoprobe Electron Diffraction Study of Surface Phases in $\mathrm{LiCoO}_{2}$

F. Cosandey, J.F. Al-Sharab, N. Pereira, F. Badway, and G. G. Amatucci

Structural features of RF magnetron sputter deposited Al-Fe and

Al-Cu thin films

S. Lallouche and M.Y. Debili

Structural Investigation of a Layered Carbon Nitride Polymer

by Electron Diffraction

M. Döblinger, B.V. Lotsch, L. Seyfarth, J. Senker, and W. Schnick

Measuring the particle density of a nanocrystal deposit using DF images and a reciprocal space analysis

P. Donnadieu

Towards a quantitative understanding of precession electron diffraction 189

A.S. Eggeman, T.A. White, and P.A. Midgley

Electron crystallography by quantitative CHEF

F. Houdellier and M.J. Hÿtch

Precession Electron Diffraction for the characterization of twinning

in pseudo-symmetrical crystals: case of coesite

D. Jacob, P. Cordier, J.P. Morniroli, and H.P. Schertl

Electron precession characterization of pseudo-merohedral twins

in the $\mathrm{LaGaO}_{3}$ perovskite

G. Ji, J.P. Morniroli, G.J. Auchterlonie, and D. Jacob

Kikuchi electron double diffraction

R.K. Karakhanyan and K.R. Karakhanyan

The structure of the complex oxide $\mathrm{PbMnO}_{2.75}$ solved

by precession electron diffraction

H. Klein

Software Precession Electron Diffraction

C.T. Koch, P. Bellina, and P.A. van Aken

A new method for electron diffraction based analysis of phase fractions and texture in thin films of metallic nano-crystals

J.L. Lábár, P.B. Barna, O. Geszti, R. Grasin, G. Lestyán, F. Misják, G. Radnóczi,

G. Sáfrán, and L. Székely

Local structures of metallic glasses studied by experimental RDF

and model refinement 205

G. Li, K.B. Borisenko,Y. Chen, E. Ma, and D.J.H. Cockayne 
Three groups of hexagonal phases and their relation to the i-phase in $\mathrm{Zn}-\mathrm{Mg}-\mathrm{RE}$ alloy 207

M.R. Li, S. Hovmöller, and X.D. Zou

Diffraction analysis of incommensurate modulation in "chain-ladder" composite crystal $(\mathrm{Sr} / \mathrm{Ca})_{14} \mathrm{Cu}_{24} \mathrm{O}_{41}$

O. Milat, K. Salamon, S. Tomić, T. Vuletić, and T. Ivek

Contribution of electron precession to the study of crystals displaying small symmetry departures

J.P. Morniroli, G. Ji, D. Jacob, and G.J. Auchterlonie

The symmetry of microdiffraction electron precession patterns

J.P. Morniroli and P. Stadelmann

Measurement of GaAs structure factors from the diffraction of parallel and convergent electron nanoprobes

K. Müller, M. Schowalter, A. Rosenauer, D. Lamoen, J. Titantah, J. Jansen, and K. Tsuda

Differential Electron Diffraction

P.N.H. Nakashima

Atomic Structure Determination by “Observing” Structural Phase in 3-Beam CBED Patterns.

P.N.H. Nakashima, A.F. Moodie, and J. Etheridge

Automatic space group determination using precession electron diffraction patterns

P. Oleynikov, S. Hovmöller, and X.D. Zou

Compositional dependence of the (200) electron diffraction in dilute III-V semiconductor solid solutions .

O. Rubel, I. Nemeth, W. Stolz, and K. Volz,

Investigation of the local crystal lattice parameters in SiGe nanostructures by convergent-beam electron diffraction analysis

E. Ruh, E. Mueller, G. Mussler, and D. Gruetzmacher

Computer simulation of electron nanodiffraction

from polycrystalline materials.

K. Sugio and X. Huang

An analytical approach of the HOLZ lines splitting on relaxed samples

J. Thibault, C. Alfonso, L. Alexandre, G. Jurczak, C. Leroux, W. Saikaly, and A. Charaï

ELDISCA C\# - a new version of the program for identifying electron diffraction patterns

J. Thomas and T. Gemming

Mixing Real and Reciprocal Space

R.D. Twesten, P.J. Thomas, H. Inada, and Y. Zhu 
Structure solution of intermediate tin oxide, $\mathrm{SnO}_{2-\mathrm{x}}$, by electron precession 235 T.A. White, S. Moreno, and P.A. Midgley

"Phase-scrambling" multislice simulations of precession electron diffraction 237 T.A. White, A.S. Eggeman, and P.A. Midgley

\section{I2.3 Holography}

High-Resolution Electron Holography on Ferroelectrics

M. Linck, H. Lichte, A. Rother, F. Röder, and K. Honda

Imaging parameters for optimized noise properties in high-resolution off-axis holograms in a Cs-corrected TEM

M. Linck

Partial coherence in inelastic holography

J. Verbeeck, G. Bertoni, D. Van Dyck, H. Lichte, and P. Schattschneider

FIB prepared and Tripod polished prepared $p-n$ junction specimens examined by off-axis electron holography

C. Ailliot, J.P. Barnes, F. Bertin, D. Cooper, J.M. Hartmann, and P. Rivallin

Modelling kink vortices in high- $T_{\mathrm{c}}$ superconductors

M. Beleggia, G. Pozzi, and A. Tonomura

Off-axis electron holography of FIB-prepared semiconductor specimens with $\mathbf{m V}$ sensitivity.

D. Cooper, R. Truche, P. Rivallin, J. Hartmann, F. Laugier, F. Bertin, and A. Chabli

Off-axis electron holography and the FIB, a systematic study of the artefacts observed in semiconductor specimens.

D. Cooper, C. Ailliot, R. Truche, J. Hartmann, J. Barnes, and F. Bertin

Analytical TEM and electron holography of magnetic field distribution in nanocrystalline Co layers deposited on $\mathrm{Cu}$

B. Dubiel, D. Wolf, E. Stepniowska, and A. Czyrska-Filemonowicz

Electron Holography with Cs-corrected Tecnai F20 - elimination of the incoherent damping introduced by the biprism in conventional electron microscopes

D. Geiger, A. Rother, M. Linck, H. Lichte, M. Lehmann, M. Haider, and B. Freitag

Can the discontinuity in the polarity of the oxide layers at the interface $\mathrm{SrTiO}_{3}-\mathrm{LaAlO}_{3}$ be resolved by using Electron Holography with Cs-corrected TEM?

D. Geiger, S. Thiel, J. Mannhart, and H. Lichte

Energy-filtered DBI/H

R.A. Herring

Strain determination by dark-field electron holography 261

F. Houdellier, M.J. Hÿtch, F. Hüe, and E. Snoeck 
Nonlinear Electron Inline Holography 263

C.T. Koch, B. Rahmati, and P.A. van Aken

Electron Holography: Performance and performance limits

265

H. Lichte

Reconstruction methods for in-line electron holography of nanoparticles

L. Livadaru, M. Malac, and R.A. Wolkow

Electron holography of soot nanoparticles

M. Pawlyta, C.W. Tai, J.-N. Rouzaud, and Y. Lereah

Holographic tomography of electrostatic potentials in semiconductor devices .... 271 P.D. Robb and A.C. Twitchett-Harrison

Electron Holography on the charge modulated structure

F. Röder, A. Rother, W. Mader, T. Bredow, and H. Lichte

Correction of the object wave using iteratively reconstructed local object tilt and thickness.

K. Scheerschmidt

Extended field of view for medium resolution electron holography

at Philips CM 200 Microscope

J. Sickmann, P. Formánek, M. Linck, and H. Lichte

Electron holography of biological and organic objects

P. Simon

Magnetic configurations of isolated and assemblies of iron $30 \mathrm{~nm}$ nanocubes studied by electron holography

E. Snoeck, C. Gatel, L.M. Lacroix, T. Blon, J. Carrey, M. Respaud, S. Lachaize, and B. Chaudret

Electron holography study of ferroelectric solid solutions

C.W. Tai and Y. Lereah

Digital holographic interference microscopy of phase microscopic objects investigation

T.V. Tishko, D.N. Tishko, and V.P. Titar

Reconstruction of 3D (Ge,Si) islands by 2D phase mapping

C.L. Zheng, H. Kirmse, I. Häusler, K. Scheerschmidt, and W. Neumann

\section{I2.4 Tomography}

Quantitative electron tomography of biological structures using elastic and inelastic scattering 289

R.D. Leapman, M.A. Aronova, A.A. Sousa, G. Zhang, and M.F. Hohmann-Marriott

Discrete tomography in materials science: less is more?

S. Bals, K.J. Batenburg, and G. Van Tendeloo 
Towards atomic-scale bright-field electron tomography for the study of fullerene-like nanostructures 293

M. Bar Sadan, L. Houben, S. G. Wolf, A. Enyashin, G. Seifert, R. Tenne, and K. Urban

DART explained:

K.J. Batenburg, S. Bals, J. Sijbers, and G. Van Tendeloo

Optical depth sectioning of metallic nanoparticles in the aberration-corrected scanning transmission electron microscope

G. Behan, A.I. Kirkland, and P.D. Nellist

3D-Geometrical and chemical quantification of $\mathrm{Au} @ \mathrm{SiO}_{\mathrm{x}}$ nano-composites in HAADF-STEM imaging mode

S. Benlekbir, T. Epicier, M. Martini, and P. Perriat

Electron tomography of mesostructured cellular foam silica

E. Biermans, S. Bals, E. Beyers, D. Wolf, J. Verbeeck, P. Cool, and G. Van Tendeloo

A Study of Stacked Si Nanowire Devices by Electron Tomography.

P.D. Cherns, C. Dupré, D. Cooper, F. Aussenac, A. Chabli, and T. Ernst

Simulation of the electron radiation damage in an amorphous Ge sample

M.D. Croitoru, D. Van Dyck, S. Le Roux, and P. Jund

Observation of Three-dimensional Elemental Distribution.

N. Endo, C. Hamamoto, H. Nishioka, and T. Oikawa

HAADF-TEM Tomography of the precipitation state in an Al-Zn-Mg alloy

T. Epicier, S. Benlekbir, and F. Danoix

STEM electron tomography of gold nanostructures

J.C. Hernandez, M.S. Moreno, E.A. Coronado, and P.A. Midgley

Three-dimensional imaging of semiconductor nanostructures

by compositional-sensitive diffraction contrast electron tomography studies

J.C. Hernandez, A.M. Sanchez, R. Beanland, and P.A. Midgley

A full tilt range goniometer inside a TEM goniometer

X.J. Xu, A. Lockwood, R. Gay, J.J. Wang, Y. Peng, B.J. Inkson, and G. Möbus

Four-dimensional STEM-EELS Tomography.

K. Jarausch, D. Leonard, R. Twesten, and P. Thomas

Embedment-free section electron microscopy (EM):

a highly potential advantage in application to EM tomography.

H. Kondo and T. Oikawa

Quantification and Segmentation of Electron Tomography

Data- Exemplified at ErSi 2 Nanocrystals in $\mathrm{SiC}$

J. Leschner, J. Biskupek, A. Chuvilin, and U. Kaiser

3-D TEM observation of xenon nano-precipitates in aluminium crystals

M. Song, H. Matsumoto, M. Shimojo, and K. Furuya 
Dark-field TEM tomography of ordered domain morphology in $\mathbf{a ~} \mathrm{Ni}_{4} \mathrm{Mo}$ alloy

K. Kimura, K. Matsuyama, S. Hata, and S. Matsumura

Optimum optical condition of Tomography for thick samples

S. Motoki, C. Hamamoto, H. Nishioka, Y. Okura, Y. Kondo, and H. Jinnai

3-dimensional nanoparticle analysis using electron tomography

T. Oikawa, D. Alloyeau, C. Ricolleau, C. Langlois, Y. Le Bouar, and A. Loiseau

Electron Tomography of ZnO Nanocones with Secondary Signals in TEM

V. Ortalan, Y. Li, E.J. Lavernia, and N.D. Browning

Quantification of Nanoparticle Tomograms

Z. Saghi, X. Xu, and G. Möbus

Tomographic imaging ultra-thick specimens with nanometer resolution

E. Sourty, B. Freitag, D. Wall, D. Tang, K. Lu, and J. Loos

Three-dimensional imaging at the mesoscopic scale using STEM-in-SEM

P. Jornsanoh, G. Thollet, C. Gauthier, and K. Masenelli-Varlot

Three-dimensional potential mapping of nanostructures

with electron-holographic tomography

D. Wolf, A. Lenk, and H. Lichte

Design of high-speed tomography with the 3MV ultrahigh voltage

electron microscope.

K. Yoshida, R. Nishi, and H. Mori

The point spread function assessment of $\mathrm{MeV}$ electron imaging quality

for thick specimens

F. Wang, H.-B. Zhang, M. Cao, R. Nishi, K. Yoshida, and A. Takaoka

Relevance of the minimum projection number to specimen structures

for high-quality electron tomography

H.-B. Zhang, M. Cao, Y. Lu, C. Li, R. Nishi, and A. Takaoka

\section{I2.5 EELS/EFTEM}

Atomic-Scale Chemical Imaging of Composition and Bonding by Aberration-Corrected Microscopy

D.A. Muller, L. Fitting Kourkoutis, M. Murfitt, J.H. Song, H.Y. Hwang, J. Silcox,

N. Dellby, and O.L. Krivanek

EMCD with nm Resolution and Below: Experiments, Proposals, and a Paradox

P. Schattschneider, M. Stöger-Pollach, F. Tian, and J. Verbeeck

Combining electronic and optical spectroscopy at the nanometer scale in a STEM

S. Mazzucco, R. Bernard, M. Kociak, O. Stéphan, M. Tencé, L.F. Zagonel, F.J. Garcia de Abajo, and C. Colliex 
Deconvolution of core loss electron energy loss spectra 353

G. Bertoni and J. Verbeeck

Obtaining the loss function from angle resolved electron energy loss spectra 355

G. Bertoni, J. Verbeeck, and F. Brosens

Revisiting the determination of carbon $\mathrm{sp}^{2} / \mathrm{sp}^{3}$ ratios via analysis of the EELS carbon K-edge.

R. Brydson, Z. Zhili, and A. Brown

Orbital and spin sum rules for electron energy loss magnetic

chiral dichroism: Application to metals and oxides

L. Calmels, B. Warot, F. Houdellier, P. Schattschneider, C. Gatel, V. Serin, and E. Snoeck

Probing bright and dark surface plasmon modes in individual and coupled Au nanoparticles using a fast electron beam 361

M.-W. Chu, V. Myroshnychenko, F.J. García de Abajo, and C.H. Chen

Dual energy range EELS spectrum imaging using a fast beam switch 363

A.J. Craven, M. MacKenzie, and S. McFadzean

Determination of local composition of Li-Si alloys

by Electron Energy-Loss Spectroscopy

J. Danet, D. Guyomard, T. Brousse, and P. Moreau

Elemental and bond mapping of complex nanostructures by MLS analysis of EELS spectrum-imaging data

F. de la Peña, R. Arenal, O. Stephan, M. Walls, A. Loiseau, and C. Colliex

EELS analysis of plasmon resonance in the $U V$-vis energy range

of metal alloy nanoparticles.

J.W.L. Eccles, U. Bangert, and P. Christian

Anisotropic effects in ELNES of the O-K edge in rutile: a case of trichroism

V. Mauchamp, T. Epicier, and J.C. Le Bossé

Dissimilar cation migration in (001) and (110) $\mathrm{La}_{2 / 3} \mathrm{Ca}_{1 / 3} \mathrm{MnO}_{3}$ thin films

S. Estrade, I.C. Infante, F. Sanchez, J. Fontcuberta, F. de la Peña, M. Walls,

C. Colliex, J. Arbiol, and F. Peiró

Energy-loss near edge structures of $\mathrm{Cr}_{2} \mathrm{O}_{3}, \mathrm{CrO}_{2}$ and $\mathrm{YCrO}_{4}$ phases

M.S. Moreno, E. Urones-Garrote, and L.C. Otero-Díaz

Distortion corrections of ESI data cubes for magnetic studies

C. Gatel, B. Warot-Fonrose, F. Houdellier, and P. Schattschneider

Optimisation of the Positions and the Width of the Energy Windows

for the Recording of EFTEM Elemental Maps.

B. Gralla and H. Kohl

Band gap mapping using monochromated electrons

L. Gu, W. Sigle, C.T. Koch, V. Srot, J. Nelayah, and P.A. van Aken 
StripeSTEM, a new method for the isochronous acquisition of HAADF images and monolayer resolved EELS 383

M. Heidelmann, L. Houben, J. Barthel, and K. Urban

Comparing Transmission Electron Microscopy (TEM) and Tomographic Atom Probe (TAP) through Measurements of Thin Multilayers

T. Heil, P. Stender, G. Schmitz, and H. Kohl

Development of a Process for Cleaning a TEM Column by Chemical Etching of Oxygen Radicals

S. Horiuchi, T. Hanada, and M. Ebisawa

Low loss EELS study of gold nanoparticles using a monochromated TEM 389

S. Irsen, N.P. Pasoz, and M. Giersigr

Analytical RPA response of Carbon and BN single-walled nanotubes:

Application to EELS and wave loss spectra...

P. Joyes, O. Stéphan, M. Kociak, A. Zobelli, and C. Colliex

Improvement of energy resolution of VEELS spectra with deconvolution method for electronic and optical properties analysis on ferroelectric oxides in nano-scale

T. Kiguchi, N. Wakiya, K. Shinozaki, and T.J. Konno

Low Loss Electron Energy Spectroscopy on $\mathrm{LiFePO}_{4}$

for Li ion Battery Applications

M. Kinyanjui, U. Kaiser, M.Wohlfahrt-Mehrens, J. Li, and D. Vainkin

Atomic-resolution studies of complex oxide materials using in-situ scanning transmission electron microscopy

G. Yang, Y. Zhao, and R.F. Klie

Low-loss EELS measurements on an oxide multilayer system using monochrome electrons

G. Kothleitner, B. Schaffer, and M. Dienstleder

White noise subtraction for calculating the two-particle-structure factor from inelastic diffractograms

C. Kreyenschulte and $\mathrm{H}$. Kohl

Local Analysis of $\mathrm{BaTiO}_{3} / \mathrm{SrTiO}_{3}$ interfaces by STEM-EELS

H. Kurata, R. Kozawa, M. Kawai, Y. Shimakawa, and S. Isoda

Experimental conditions and data evaluation for quantitative EMCD measurements in the TEM.

H. Lidbaum, J. Rusz, A. Liebig, B. Hjörvarsson, P.M. Oppeneer, E. Coronel,

O. Eriksson, and K. Leifer

Investigation of the valency distribution in $\mathrm{Cu}_{1.2} \mathrm{Mn}_{1.8} \mathrm{O}_{4}$

using quantitative EELS near-edge structures analysis

C. Maunders, B.E. Martin, P. Wei, A. Petric, and G.A. Botton 
EELS mapping of surface plasmons in star-shaped gold nanoparticles: morphological behaviour of optical properties from star to sphere 409

S. Mazzucco, O. Stéphan, M. Kociak, and C. Colliex

Fast local determination of phases in $\mathrm{Li}_{x} \mathrm{FePO}_{4}$

P. Moreau, V. Mauchamp, and F. Boucher

EELS/EFTEM in life science: proof of the presence of $\mathrm{H}_{2} \mathrm{O}_{2}$ in human skin by Ce deposition in melanosomes.

E. Müller, M. Droste, K. Gläser, and R. Wepf

Phase separation study of annealed SiOx films through energy filtered scanning transmission electron microscope

G. Nicotra, C. Bongiorno, C. Spinella, and E. Rimini

Phase Identification of Aluminium Oxide Phases by Analysis of the Electron Energy-loss Near Edge Structure

D. Park, T.E. Weirich, and J. Mayer

Valence sensitivity of Fe- $\mathrm{L}_{2,3}$ white-line ratios extracted from EELS.

T. Riedl, R. Serra, L. Calmels, and V. Serin

Calculation of inelastic scattering events within second order

QED - Implications of fully relativistic scattering

A. Rother

Role of asymmetries for EMCD sum rules.

J. Rusz, H. Lidbaum, A. Liebig, P. Novák, P.M. Oppeneer, O. Eriksson, K. Leifer, and B. Hjörvarsson

Smart acquisition EELS

K. Sader, P. Wang, A.L. Bleloch, A. Brown, and R. Brydson

EELS fine structure tomography using spectrum imaging

Z. Saghi, X. Xu, and G. Möbus

Shift in electron energy loss compared for different nickel silicides in a Pt alloyed thin film.

M. Falke, T. Schaarschmidt, H. Schletter, R. Jelitzki, S. Schulze, G. Beddies,

M. Hietschold, M. MacKenzie, A.J. Craven, and A. Bleloch

Distribution of Fe and In dopants in ZnO: A combined EELS/EDS analysis....... 431

H. Schmid and W. Mader

Changes in the Soot Microstructure during Combustion studied

by SEM, TEM, Raman and EELS

M.E. Schuster, M. Knauer, N.P. Ivleva, R. Niessner, D.S. Su, and R. Schlögl

EELS and EFTEM-investigations of aluminum alloy 6016 concerning

the elements $\mathrm{Al}, \mathrm{Si}$ and $\mathrm{Mg}$

S. Schwarz and M. Stöger-Pollach

EELS modelling using a pseudopotential DFT code

C.R. Seabourne, A.J. Scott, and R. Brydson 
The EELS spectrum database 439

T. Sikora and V. Serin

STEM-EELS analysis of interface magnetic moments in $\mathrm{Fe}(\mathbf{1 0 0}) / \mathrm{Co}(\mathrm{bcc})$ superlattices

R. Serra, L. Calmels, V. Serin, B. Warot-Fonrose, and S. Andrieu

EMCD at high spatial resolution: comparison of STEM with EELS profiling .... 443 M. Stöger-Pollach, P. Schattschneider, J. Perkins, D. McComb

Elemental, Chemical and Physical State Mapping in Three-Dimensions using EELS-SI Tomography

P.J. Thomas, C. Booth, R. Harmon, S. Markovic, R.D. Twesten, and K. Jarausch

Sub-0.5 eV EFTEM Mapping using the Zeiss SESAM

C.T. Koch, W. Sigle, J. Nelayah, L. Gu, V. Srot, and P.A. van Aken

Acquisition of the EELS data cube by tomographic spectroscopic imaging

W. Van den Broek, J. Verbeeck, S. De Backer, D. Schryvers, and P. Scheunders

A low electron fluence EELS study of Fe-coordination within ferrihydrite and phosphorous doped ferrihydrite nanoparticles

G. Vaughan, A.P. Brown, R. Brydson, and K. Sader

Optimal aperture sizes and positions for EMCD experiments

J. Verbeeck, C. Hébert, S. Rubino, P. Novák, J. Rusz, F. Houdellier, C. Gatel, and P. Schattschneider

Chemical analysis of nickel silicides with high spatial resolution

by combined EDS and EELS (ELNES)

E. Verleysen, O. Richard, H. Bender, D. Schryvers, and W. Vandervorst

Retrieving dielectric function by VEELS

L. Zhang, J. Verbeeck, R. Erni, and G. Van Tendeloo

\section{I2.6 In-situ TEM and dynamic TEM}

Some Recent Materials Applications of In Situ High Resolution

Electron Microscopy

R. Sinclair, S.K. Kang, K.H. Kim, and J.S. Park

Melting and solidification of alloys embedded in a matrix at nanoscale

$K$. Chattopadhyay, $V$. Bhattacharya, and $K$. Biswas

Advances in transmission electron microscopy: in situ nanoindentation and in situ straining experiments

J.Th.M. De Hosson

Observing Nanosecond Phenomena at the Nanoscale with the Dynamic

Transmission Electron Microscope.

G.H. Campbell, N.D. Browning, J.S. Kim, W.E. King, T. LaGrange, B.W. Reed, and M.L. Taheri 
TEM characterization of nanostructures formed from $\mathrm{SiGeO}$ films: effect of electron beam irradiation 467

C. Ballesteros, M.I. Ortiz, B. Morana, A. Rodríguez, and T. Rodríguez

In situ Lorentz microscopy in an alternating current magnetic field 469

Z. Akase, H. Kakinuma, D. Shindo, and M. Inoue

In-situ transmission electron microscopy investigation of $\mathrm{TiO}$ islands nucleating on $\mathrm{SrTiO}_{3}(100)$ and (110) surfaces at high temperature 471 P.J. Bellina, F. Phillipp, and P.A. van Aken

Probing integration strength of colloidal spheres self-assembled from $\mathrm{TiO}_{2}$ nanocrystals by in-situ TEM indentation

C.Q. Chen, Y.T. Pei, and J.Th.M. De Hosson

Installation and operation of an in situ electron microscopy facility

M.W. Fay, H.K. Edwards, M. Zong, K.J. Thurecht, S.M. Howdle, and P.D. Brown

Bringing chemical reactions to life: environmental transmission electron microscopy (E-TEM)

B. Freitag, S.M. Kim, D.N. Zakharov, E.A. Stach, and D.J. Stokes

Dynamic in situ experiments in a $1 \AA \AA$ double aberration corrected environment

P.L. Gai and E.D. Boyes

A very high temperature $\left(2000^{\circ} \mathrm{C}\right)$ stage for atomic resolution in situ ETEM

P.L. Gai and E.D. Boyes

Environmental High Resolution Electron Microscopy With a Closed Ecell:

Application to Catalysts

S. Giorgio, M. Cabié, and C.R. Henry

Pulsed-mode photon and electron microscopy surveyed

A. Howie

In-situ Observation of Nano-particulate Gold Catalysts during Reaction by Closed-type Environmental-cell Transmission Electron Microscope.

T. Kawasaki, H. Hasegawa, K. Ueda, and T. Tanji

In situ transmission electron microscopy on leadzirconate-titanate under electrical field

J. Kling, L. Schmitt, H.-J. Kleebe, and H. Fuess

Elongation of Atomic-size Wires: Atomistic Aspects and Quantum

Conductance Studies

M. Lagos, V. Rodrigues, and D. Ugarte

Atomic-size Silver Nanotube

M. Lagos, F. Sato, J. Bettini, V. Rdrigues, D. Galvão, and D. Ugarte

In-situ TEM mechanical testing of a Si MEMS nanobridge 495

A.J. Lockwood, R.J.T. Bunyan, and B.J. Inkson 
In-situ TEM nanoindentation and deformation of Si-nanoparticle clusters

A.J. Lockwood, and B.J. Inkson

Electron Holography of in-situ ferroelectric polarisation switching

Ch. Matzeck, B. Einenkel, H. Müller, and H. Lichte

Development of fast CCD Cameras for in-situ Electron Microscopy

B. Mollon, L. Tsung, M. Pan, Y. Jia, P. Mooney, and C. Mao

In situ characterization of the mechanical properties of nanoparticles and nanoscale structures.

J. Deneen Nowak, Z.W. Shan, and O.L. Warren

In-situ engineering of nanostructures with near atomic precision and property measurements.

L.-M. Peng, M.S. Wang, Y. Liu, and Q. Chen

In-situ TEM investigation of the contrast of nanocrystals embedded in an amorphous matrix

M. Peterlechner, T. Waitz, and H.P. Karnthaler

In situ HRTEM - Image corrected and monochromated Titan equipped with environmental cell.

J.B. Wagner, J.R. Jinschek, T.W. Hansen, C.B. Boothroyd, and R.E. Dunin-Borkowski

The surface dynamics of the transient oxidation stages of $\mathrm{Cu}$ and $\mathrm{Cu}$ binary alloys.

J. C. Yang, Z. Li, L. Sun, G.W. Zhou, J.E. Pearson, J.A. Eastman, D.D. Fong,

P.H. Fuoss, P.M. Baldo, and L.E. Rehn

In-situ TEM for altering nanostructures and recording the changes at an atomic resolution

X.F. Zhang and T. Kamino

\section{I3 SEM/FIB Instrumentation and Methods}

\section{I3.1 SEM instrumentation and methods}

Aberration correction in SEM: Relaunching an old project 515

J. Zach

Changes and reversals of contrasts in SEM

J. Cazaux

Surface potential and SE detection in the SEM

J. Cazaux

On the Spatial Resolution and Nanoscale Features Visibility

in Scanning Electron Microscopy and Low-Energy Scanning Transmission

Electron Microscopy.

V. Morandi, A. Migliori, F. Corticelli, and M. Ferroni 
Scanning electron microscopy techniques for cross-sectional analyses of thin-film solar cells

D. Abou-Ras, U. Jahn, J. Bundesmann, R. Caballero, C.A. Kaufmann, J. Klaer,

M. Nichterwitz, T. Unold, and H.W. Schock

Maximising EBSD acquisition speed and indexing rate

S. Asahina, F. Charles, K. Dicks, and N. Erdman

Helium ion microscope: advanced contrast mechanisms for imaging and analysis of nanomaterials

D.C. Bell, L.A. Stern, L. Farkas, and J.A. Notte

Hygroscopic properties of individual aerosol particles

from aluminum smelter potrooms determined by environmental scanning electron microscopy

N. Benker, M. Ebert, P.A. Drablos, D.G. Ellingsen, Y. Thomassen, and S. Weinbruch

Analysis of individual aerosol particles by automated scanning electron microscopy

N. Benker, K. Kandler, M. Ebert, and S. Weinbruch

A new quantitative height standard for the routine calibration

of a 4-quadrant-large-angles-BSE-detector

D. Berger, M. Ritter, M. Hemmleb, G. Dai, and T. Dziomba

SEM-EDS for effective surface science and as a next generation defect review tool for nanoparticle analysis?

E.D. Boyes

Detection of Signal Electrons by Segmental Ionization Detector

P. Cernoch and J. Jirak

Low-voltage Scanning Transmission Electron Microscopy

of InGaAs nanowires.

L. Felisari, V. Grillo, F. Jabeen, S. Rubini, and F. Martelli

Secondary Electrons Characterization of Hydrogenated Dilute Nitrides

L. Felisari, V. Grillo, S. Rubini, F. Martelli, R. Trotta, A. Polimeni, M. Capizzi, and L. Mariucci

Mapping of the local density of states with very slow electrons in SEM

Z. Pokorná and L. Frank

Thickness and composition measurement of thin TEM samples with EPMA and the thin film analysis software STRATAGem.

F. Galbert and D. Berger

Automatic acquisition of large amounts of 3D data at the ultrastructural level, using serial block face scanning electron microscopy

C. Genoud, J. Mancuso, S. Monteith, and B. Kraus 
MCSEM- a modular Monte Carlo simulation program

for various applications in SEM metrology and SEM photogrammetry

D. Gnieser, C.G. Frase, H. Bosse, and R. Tutsch

Wien filter electron optical characteristics determining using shadow

projection method

I. Vlček, M. Horáček, and M. Zobač

Strain related Contrast mechanisms in crystalline materials imaged with AsB detection.

H. Jaksch

Low Loss BSE imaging with the EsB Detection system

on the Gemini Ultra FE-SEM.

H. Jaksch

Accurate calculations of thermionic electron gun properties

P. Jánský, B. Lencová, and J. Zlámal

Scintillation SE Detector for Variable Pressure Scanning

Electron Microscope

J. Jirak, P. Cernoch, V. Nedela, and J. Spinka

The stability of retained austenite in supermartensitic stainless steel (SMSS)

examined by means of SEM/EBSD.

M. Karlsen, J. Hjelen, Ø. Grong, G. Rorvik, R. Chiron, and U. Schubert

In-situ EBSD studies of hydrogen induced stress cracking (HISC)

in pipelines of super-duplex stainless steel

M. Karlsen, J. Wåsjø, J. Hjelen, Ø. Grong, G. Rorvik, R. Chiron, and U. Schubert

E-beam hardening SEM glue for fixation of small objects in the SEM

S. Kleindiek, A. Rummel, and K. Schock

Development of the charging reduction system by electron beam irradiation

for scanning electron microscopes

Y. Kono, O. Suzuki, and K. Honda

Aberrations of the cathode lens combined with a focusing magnetic/immersion-magnetic lens

I. Konvalina, I. Müllerová, and M. Hovorka

Identification possibilities of micro/nanoparticles and nanocomposites

in forensic practice

M. Kotrly, I. Turkova, and V. Grunwaldova

Mass thickness determination of thin specimens using high-resolution scanning electron microscopy.

V. Krzyzanek and R. Reichelt

Benefits of Low Vacuum SEM for EBSD Applications

K. Kunze, St. Buzzi, J. Löffler, and J.-P. Burg 
In-situ combination of SEMPA, STM, and FIB for magnetic imaging and nanoscale structuring. 577

J. Mennig, J. Kollamana, S. Gliga, S. Cherifi, F. Matthes, D.E. Bürgler, and C.M. Schneider

Characterisation of the subgrain structure of the aluminium alloy AA6082 after homogenization and hot forming by EBSD. 579

S. Mitsche, P. Sherstnev, C. Sommitsch, T. Ebner, and M. Hacksteiner

An improved detection system for low energy Scanning Transmission Electron Microscopy .581

V. Morandi, A. Migliori, P. Maccagnani, M. Ferroni, and F. Tamarri

Thickness determination of thin samples by transmission measurements in a scanning electron microscope.

E. Müller

Role of the high-angle BSE in SEM imaging

I. Müllerová and L. Frank

Experimental and simulated signal amplification in variable pressure SEM

V. Neděla, P. Jánský, B. Lencová, and J. Zlámal

Study of highly-aggressive samples using the variable pressure SEM

J. Runštuk and V. Neděla

Characterization of the focusing properties of polycapillary X-ray lenses in the scanning electron microscope

J. Nissen, D. Berger, B. Kanngießer, I. Mantouvalou, and T. Wolff

Numerical Simulation of Signal Transfer in Scintillator-Photomultiplier Detector

L. Novák

In-situ Electrical Measurements on Nanostructures in a Scanning Electron Microscope

M. Noyong, K. Blech, F. Juillerat, H. Hofmann, and U. Simon

3D Sculptures From SEM Images.

R. Pintus, S. Podda, and M. Vanzi

Influence of tilt of sample on axial beam properties

T. Radlička and B. Lencová

Experimental determination of the total scattering cross section of water vapour and of the effective beam gas path length in a low vacuum scanning electron microscope. 601

J. Rattenberger, J. Wagner, H. Schröttner, S. Mitsche, M. Schaffer, and A. Zankel

Response function of the semiconductor detector of backscattered electrons in SEM

E.I. Rau, S.A. Ditsman, F.A. Luk'yanov, and R.A. Sennov 
Main principles of microtomography using backscattered electrons 605 E.I. Rau

Considerations of some charging effects on dielectrics by electron beam irradiation

E.I. Rau, E.N. Evstaf'eva, R.A. Sennov, and E. Plies

The reduction of pileup effects in spectra collected with silicon drift detectors 609

T. Elam, R. Anderhalt, A. Sandborg, J. Nicolosi, and D. Redfern

High-temperature oxidation of steel in the ESEM with subsequent scale characterisation by Raman microscopy

A. Reichmann, P. Poelt, C. Brandl, B. Chernev, and P. Wilhelm

Method to determine image sharpness and resolution in Scanning Electron Microscopy images.

B.Rieger and G.N.A van Veen

Instrumentation of an electron microscope for lithography and analysis of devices over a wide dimensional range.

G. Rosolen

Ultra-low energy, high-resolution scanning electron microscopy

L.Y. Roussel, D.J. Stokes, R.J. Young, and I. Gestmann

Non-destructive 3D imaging of the objects internal microstructure

by microCT attachment for SEM

A. Sasov

A novel use of rf-GD sputtering for sample surface preparation for SEM:

its impact on surface analysis

K. Shimizu, T. Mitani, and P. Chapon

Development of an ultra-fast EBSD detector system

M. Sofferud, J. Hjelen, M. Karlsen, T. Breivik, N.C. Krieger Lassen, and R. Schwarzer

Future prospects on EBSD speeds using a 40 nA FESEM.

M. Søfferud, J. Hjelen, M. Karlsen, D. Dingley, and H. Jaksch

High pressure imaging in the environmental scanning electron microscope (ESEM)

D.J. Stokes, J. Chen, W.A.J. Neijssen, E. Baken, and M. Uncovsky

Cathodoluminescence spectrum-imaging in the scanning electron microscope using automated stage control.

D.J. Stowe, P.J. Thomas, and S.A. Galloway

Low voltage, high resolution SEM imaging for mesoporous materials

O. Takagi, S. Takeuchi, A. Miyaki, H. Ito, H. Sato, Y. Dan, M. Nakagawa, S. Kataoka,

Y. Inagi, and A. Endo 
New developments in state of the art silicon drift detectors (SDD) and multiple element SDD

R. Terborg and M. Rohde

SEM in forensic science

I. Turkova and M. Kotrly

Secondary electron imaging due to interface trapped charges

for a buried $\mathrm{SiO}_{2}$ microstructure

H.-B. Zhang, W.-Q. Li, X. Wu, and D.-W. Wu

HRSEM Secondary Electron Doping Contrast:

Theory based on Band Bending and Electron Affinity Measurements

I. Zhebova, M. Molotskii, Z. Barkay, G. Meshulam, E. Grunbaum, and Y. Rosenwaks

\section{I3.2 FIB and Dual Beam - instrumentation and methods}

3D EBSD-based orientation microscopy and 3D materials simulation tools: an ideal combination to study microstructure formation processes 641

S. Zaefferer

Capturing Sub-Nanosecond Quenching in DualBeam FIB/SEM

Serial Sectioning.

W.J. MoberlyChan and A.E. Gash

Deformation mechanisms in 1D nanostructures revealed by in situ tensile testing in an SEM/FIB.

D.S. Gianola, R. Mönig, O. Kraft, and C.A. Volkert

Focused Ion Beam Tomography of Insulating Biological

and Geological Materials

B.M. Humbel, D.A.M. de Winter, C.T.W.M. Schneijdenberg, B.H. Lich, M.R. Drury, and A.J. Verkleij

Redeposition and differential sputtering of La in TEM samples of $\mathrm{LaAlO}_{3} / \mathrm{SrTiO}_{3}$ multilayers prepared by FIB.

E. Montoya, S. Bals, and G. Van Tendeloo

Fabrication and characterization of highly reproducible,

high resistance nanogaps made by focused ion beam milling

T. Blom, K. Welch, M. Stromme, E. Coronel, and K. Leifer

TEM sample preparation on photoresist

F. Cazzaniga, E. Mondonico, E. Ricci, F. Sammiceli, R. Somaschini, S. Testai, and M. Zorz

Advanced FIB preparation of semiconductor specimens for examination by off-axis electron holography.

D. Cooper, R. Truche, A.C. Twitchett-Harrison, P.A. Midgley,

and R.E. Dunin Borkowski 
Comparison of ion- and electron-beam-induced Pt nanodeposits: composition, volume per dose, microstructure, and in-situ resistance 657

R. Córdoba, J.M. De Teresa, A. Fernández-Pacheco, O. Montero, P. Strichovanec, A. Ibarra, and M.R. Ibarra

In-line FIB TEM sample preparation induced effects on advanced fully depleted silicon on insulator transistors

V. Delaye, F. Andrieu, F. Aussenac, and C. Carabasse

The development of cryo-FIBSEM techniques for the sectioning and TEM analysis of the cell-biomaterial interface.

H.K. Edwards, M.W. Fay, C.A. Scotchford, D.M. Grant, and P.D. Brown

Three-slit interference experiments with electrons

S. Frabboni, G.C. Gazzadi, and G. Pozzi

Contrast in ion induced secondary electron images

L.A. Giannuzzi, M. Utlaut, and L. Swanson

Quantitative in situ thickness determination of FIB TEM lamella by using STEM in a SEM

U. Golla-Schindler

Analysis of ion diffusion in multilayer materials by depth profiling in a Crossbeam FIB-SIMS microscope.

A. Hospach, A.M. Malik, W. Nisch, and C. Burkhardt

Growth of $\mathrm{In}_{2} \mathrm{O}_{3}$ islands on Y-stabilised $\mathrm{ZrO}_{2}$ : a study by FIB and HRTEM

J.L. Hutchison, A. Bourlange, R. Egdell, and A. Schertel

Carbon nanotubes grown in contact holes for nano electronic applications:

how to prepare TEM samples by FIB?

X. Ke, S. Bals, A. Romo Negreira, T. Hantschel, H. Bender, and G. Van Tendeloo

Advances in 3-dimensional material characterisation using simultaneous EDS and EBSD analysis in a combined FIB-SEM microscope

R. de Kloe, H. Schulz, and F. Reinauer

Investigation of the effects of the TEM specimen preparation method on the analysis of the dielectric gate stack in GaAs based MOSFET devices.

P. Longo, W. Smith, B. Miller, and A.J. Craven

Manipulation and contacting of individual carbon nanotubes inside a FIB workstation.

S.B. Menzel, H. Vinzelberg, and T. Gemming

High volume TEM-sample preparation using a wafer saving in-line preparation tool

U. Muehle, S. Jansen, R. Schuetten, R. Prang, R. Schampers, and R. Lehmann

The influence of beam defocus on volume growth rates for electron beam induced platinum deposition 683

H. Plank, M. Dienstleder, G. Kothleitner, and F. Hofer 
Reducing of ion beam induced surface damaging using "low voltage" focused ion beam technique for transmission electron microscopy sample preparation 685

R. Salzer, M. Simon, A. Graff, F. Altmann, and L. Pastewka M. Moseler

DualBeam FIB application of 3D EDXS for superalloy

$\delta$-phase characterization.

J. Wagner, M. Schaffer H. Schroettner, S. Mitsche, I. Letofsky-Papst, Ch. Stotter, and Ch. Sommitsch

\section{I4 Other Microscopies}

\section{I4.1 Light and $X$-rays}

Time-resolved photoemission electron microscopy 689

G. Schönhense

Quantitative 3D imaging of cells at $50 \mathrm{~nm}$ resolution

using soft $x$-ray tomography.

C. Larabell, D.Y. Parkinson, W. Gu, C. Knoechel, G. McDermott, and M.A. Le Gros

STXM-NEXAFS of individual titanate-based nanoribbon

C. Bittencourt, A. Felten, X. Gillon, J.-J. Pireaux, E. Najafi, A.P. Hitchcock, X. Ke,

G. Van Tendeloo, C.P. Ewels, P. Umek, and D. Arcon

The fine structure of bioreactor liver tissue seen through the eyes

of X-ray micro-computed tomography

C. Fernandes, D. Dwarte, K. Nagatsuma, M. Saito, T. Matsuura, and F. Braet

Comparing the $\mathrm{Si}(\mathrm{Li})$-detector and the silicon drift detector (SDD)

using EDX in SEM

U. Gernert

Enhancing contrast of Al traces on Si substrates using low-voltage

SEM-hosted XRM

B.C. Gundrum and J.A. Hunt

An optical demonstration of ptychographical imaging of a single defect in a model crystal.

A. Hurst, F. Zhang, and J.M. Rodenburg

HRTEM and STXM, a combined study of an individual focused-ion-beam patterned CNT

A. Felten, X. Ke, X. Gillon, J.-J. Pireaux, E. Najafi, A.P. Hitchcock, C. Bittencourt, and G. Van Tendeloo

Compact micro-CT/micro-XRF system for non-destructive 3D analysis of internal chemical composition.

A. Sasov, X. Liu, and D. Rushmer 
NanoCT: Visualising of Internal 3D-Structures with Submicrometer Resolution 707

F. Sieker, and $O$. Brunke

\section{I4.2 Scanning Probe Microscopy}

Dynamics of nanostructures on surfaces revealed by high-resolution, fast-scanning STM.

F. Besenbacher

Spin mapping on the atomic scale

R. Wiesendanger

Researching the structure of the surface of undoped $\mathrm{ZnO}$ thin films by means of Atomic Force Microscopy

N. Muñoz Aguirre, P. Tamayo Meza, and L. Martínez Pérez

Improving the structural characterization of supported on glass gold nanoparticles using Atomic Force Microscopy on vacuum conditions 715 N. Muñoz Aguirre, J.E. Rivera López, L. Martínez Pérez, and P. Tamayo Meza

$\mathrm{CO}$ and $\mathrm{O}_{2}$ chemisorption on $\mathrm{Pd}_{70} \mathrm{Au}_{30}(110)$ : evolution of the surface studied by in situ STM and complementary surface analysis techniques at elevated pressures

M.A. Languille, F.J. Cadete Santos Aires, B.S. Mun, Y. Jugnet, M.C. Saint-Lager,

H. Bluhm, O. Robach, D.E. Starr, C. Rioche, P. Dolle, S. Garaudée, P.N. Ross, and J.C. Bertolini

Height measurements on soft samples: applied force, molecules deformation and phase shift

C. Albonetti, N.F. Martínez, A. Straub, F. Biscarini, R. Pérez, and R. García

Effect of temperature on phase transition of cardiolipin liquid-crystalline aggregates studied by AFM

A. Alessandrini and $U$. Muscatello

Investigating the influence of dynamic scattering on ptychographical iterative techniques

C. Liu, T. Walther, and J.M. Rodenburg

Determination of the lateral Resolution of a Cantilever based Solid

Immersion Lens Near Field Microscope

T. Merz, K. Rebner, and R.W. Kessler

LT-STM manipulation and spectroscopy of single copper and cobalt atoms 727

E. Zupanič, R. Žitko, H.J.P. van Midden, A. Prodan, and I. Muševič

\section{I4.3 Field Ion Microscopy and Atom Probe}

3D atomic-scale chemical analysis of engineering alloys 729

A. Cerezo, E.A. Marquis, D.W. Saxey, C. Williams, M. Zandbergen, and G.D.W. Smith 
New Applications for Atom-Probe Tomography in Metals, Semiconductors and Ceramics 731

T.F. Kelly, D.J. Larson, R.L. Alvis, P.H. Clifton, S.S.A. Gerstl, R.M. Ulfig, D. Lawrence, D.P. Olson, D.A. Reinhard, and K. Stiller

Pulsed laser atom probe tomography analysis of advanced semiconductor nanostructures 733

M. Müller, A. Cerezo, G.D.W. Smith, and L. Chang

\section{I4.4 Surface Analytical Techniques}

Low Energy Electron Microscopy: A 10 Year Outlook 735

R.M. Tromp

Imaging of Surface Plasmon Waves in Nonlinear Photoemission Microscopy ..... 737 F.-J. Meyer zu Heringdorf, N.M. Buckanie, L.I. Chelaru, and N. Raß

High resolution surface analysis of metallic and biological specimens by NanoSIMS. 739

C.R.M. Grovenor

Elemental distribution profiles across $\mathrm{Cu}(\mathrm{In}, \mathrm{Ga}) \mathrm{Se}_{2}$ solar-cell absorbers acquired by various techniques

D. Abou-Ras, C.A. Kaufmann, A. Schöpke, A. Eicke, M. Döbeli, B. Gade, and T. Nunney

High resolution Kelvin force microscopy

M.A. Fenner, J. Alexander, and S. Magonov

High resolution in interferometric microscopy

M. Jobin and R. Foschia

Effects of annealing on the microstructural evolution of copper films using texture analysis

A. Moskvinova, S. Schulze, M. Hietschold, I. Schubert, R. Ecke, and S.E. Schulz

Characterisation of Ga-distribution on a silicon wafer after inline

FIB-preparation using inline ToFSIMS

U. Muehle, R. Gaertner, J. Steinhoff, and W. Zahn

First results in thin film analysis based on a new EDS software to determine composition and/or thickness of thin layers on substrates

K. Sempf, M. Herrmann, and F. Bauer

Calibration of RHEED patterns for the appraisal

of titania surface crystallography

T. Tao, R. Walton, H.K. Edwards, M.W. Fay, D.M. Grant, and P.D. Brown

Surface orientation dependent termination and work-function of in situ annealed strontium titanate.

N. Barrett, L.F. Zagonel, A. Bailly, O. Renault, J. Leroy, J.C. Cezar, N. Brookes, Shao-Ju Shih, and D. Cockayne 


\section{I5 Image analysis and Processing}

\section{I5.1 New image processing developments in Materials Science and beyond}

Structure determination of zeolites by electron crystallography 757

J. Sun, D. Zhang, Z. He, S. Hovmöller, X. Zou, F. Gramm, C. Baerlocher, and L.B. McCusker

3D electron diffraction of protein crystals: data collection, cell determination and indexing

D.G. Georgieva, L. Jiang, H.W. Zandbergen, S. Nicolopoulos, and J.P. Abrahams

Self-assembly of cholesterol-based nonionic surfactants in water.

Unusual micellar structure and transitions.

L. Abezgauz, I. Portnaya, and D. Danino

Quantitative study of anode microstructure related

to SOFC stack degradation 763

A. Faes, A. Hessler-Wyser, D. Presvytes, A. Brisse, C.G. Vayenas, and J. Van herle

New considerations for exit wavefunction restoration under aberration corrected conditions.

S.J. Haigh, L-Y. Chang, H. Sawada, N.P. Young, and A.I. Kirkland

High quality electron diffraction data by precession

S. Hovmöller, D. Zhang, J. Sun, X. Zou, and P. Oleynikov

Optimal noise filters for high-resolution electron microscopy

of non-ideal crystals

K. Ishizuka, P.H.C. Eilers, and T. Kogure

Noise considerations in the application of the transport of intensity equation for phase recovery

S. McVitie

elmiX - An Electron Microscopy Software Collection for Data Analysis and Education

A. Reinholdt and T.E. Weirich

Speed considerations when performing particle analysis

and chemical classification by SEM/EDS

S. Scheller

Morphological characterization of particles with very broad size distributions using program MDIST

M. Slouf, M. Lapcikova, H. Vlkova, E. Pavlova, and J. Hromadkova 


\section{I5.2 New $2 D$ and $3 D$ image processing and analysis developments in Life Science}

Multiple protein structures in one shot: maximum-likelihood image classification in 3D-EM.

S.H.W. Scheres and J.M. Carazo

Compensation and evaluation of errors of 3D reconstructions from confocal microscopic images

M. Čapek, P. Brūža, L. Kocandová, J. Janáček, L. Kubínová, and R. Vagnerová

High content image-based cytometry as a tool for nuclear fingerprinting 783

W.H. De Vos, B. Dieriks, G. Joss, and P. Van Oostveldt

Measurement of surface area of biological structures, based on 3D microscopic image data 785

L. Kubínová and J. Janáček

The imaging function for tilted samples: simulation, image analysis and correction strategies.

V. Mariani, A. Schenk, A. Engel, and A. Philippsen

4D-Microscopy

A.A. Mironov, M. Micaroni, and G.V. Beznoussenko

Strategies for high content imaging screening and analysis of primary neurons.

S. Munck and W. Annaert

Modelling and analysis of clustering and colocalization patterns in ultrastructural immunogold labelling of cell compartments based on 3-D image data

A. Vyhnal

\section{I6 Sample Preparation for Materials Science and Biology}

Modern Methods of TEM Specimen Preparation in Material Science 795 H.J. Penkalla

Ultramicrotomy in biology and materials science: an overview

H. Gnaegi, D. Studer, E. Bos, P. Peters, and J. Pierson ${ }^{3}$

Preparation of Biological Samples for Electron Microscopy. 799

H. Schwarz and B.M. Humbel ${ }^{2}$

Web sample preparation guide for transmission electron microscopy (TEM).....801 J. Ayache, L. Beaunier, J. Boumendil, G. Ehret, and D. Laub 
Novel carbon nanosheets as support for ultrahigh resolution structural analysis of nanoparticles

A. Beyer, C. Nottbohm, A. Sologubenko, I. Ennen, A. Hütten, H. Rösner, J. Mayer, and A. Gölzhäuser

A new automated plunger for cryopreparation of proteins in defined - even oxygen free - atmospheres.

F. Depoix, U. Meissner, and J. Markl

A novel method for precipitates preparation using extraction replicas combined with focused ion beam techniques

M. Dienstleder, H. Plank, G. Kothleitner, and F. Hofer

An appraisal of FIBSEM and ultramicrotomy for the TEM analysis of the cell-biomaterial interface

H.K. Edwards, M.W. Fay, S.I. Anderson, C.A. Scotchford, D.M. Grant, and P.D. Brown

Observation of the structure of aqueous polymers with cryo-SEM

A. Fujino, M. Yamashita, and N. Satoh

Lipid nanotube encapsulating method in low voltage scanning transmission electron microscopy

H. Furusho, Y. Mishima, N. Kameta, M. Yamane, M. Masuda, M. Asakawa,

I. Yamashita, A. Takaoka, and T. Shimizu

Microscopy observation of food biopolymers and related sample

preparation methods

C. Gaillard

Preparation of $\mathrm{SiC} / \mathrm{SiC}$ thin foils for TEM observations

by wedge polishing method.

M. Gec, T. Toplišek, V. Šrot, G. Dražić, S. Kobe, P.A. van Aken, and M. Čeh

Serial-section Polishing Tomography

J.A. Hunt, P. Prasad, and E. Raz.

Visualization of detergent resistant membrane rafts in human colorectal cancer cells with correlative confocal and transmission electron microscopy

K. Jahn, E.P. Kable, and F. Braet

Contribution of low tension ion-milling to heterostructural semiconductors preparation

M. Korytov, O. Tottereau, J.M. Chauveau, and P. Vennéguès

Metallographic characterization of $\mathrm{MgH}_{2}-\mathrm{Mg}$ system

M. Vittori Antisari, A. Montone, A. Aurora, M.R. Mancini, D. Mirabile Gattia, and L. Pilloni

LSM tomography of 2-cell mouse embryo

M.A. Pogorelova, V.A. Golichenkov, and V.N. Pogorelova

Microwave-assisted sample preparation for life science

J.A. Schroeder 
Comparison TEM specimen preparation of perovskite thin films by conventional Ar ion milling and tripod polishing

E. Eberg, A.T.J. van Helvoort, B.G. Soleim, A.F. Monsen, L.C. Wennberg, T. Tybell, and R. Holmestad

In-situ temperature measurements on TEM-specimen during ion-milling 833 M. Wengbauer, J. Gründmayer, and J. Zweck

Author Index 835 